\title{
Effect of Anthropometry and Dyslipidaemia on Birth Weight
}

\author{
Edward Delali Darku1, Afu Clifford Jr.'2, Martin Kwesi Darku³ \\ ${ }^{1}$ Department of Medical Laboratory Sciences, School of Allied Sciences, University of Health Allied Sciences, Ho, Ghana \\ ${ }^{2}$ Department of Physician Assistantship, School of Medicine, University of Health and Allied Sciences, Ho, Ghana \\ ${ }^{3}$ Ankarful Centre for Preventive Disease, Ankaful, Ghana \\ Email: edwardarku@gmail.com, cliffafu@gmail.com, delaliedward@gmail.com
}

How to cite this paper: Darku, E.D., Clifford Jr., A. and Darku, M.K. (2017) Effect of Anthropometry and Dyslipidaemia on Birth Weight. Open Access Library Journal, 4: e3733.

https://doi.org/10.4236/oalib.1103733

Received: June 10, 2017

Accepted: July 11, 2017

Published: July 14, 2017

Copyright $\odot 2017$ by authors and Open Access Library Inc.

This work is licensed under the Creative Commons Attribution International License (CC BY 4.0).

http://creativecommons.org/licenses/by/4.0/

\begin{abstract}
The period of pregnancy is a very important aspect of fetal growth and development. Maternal weight gain during pregnancy is associated with fetal macrosomia. Generally, delays in low maternal weight gain have been linked to limitations in fetal growth and development, and there is some evidence that low maternal weight gain is associated with an increased risk of pre-term delivery. Objective: To determine the effect of hyperlipidaemia during pregnancy on neonatal growth and birth weight. Methodology: This was a prospective cross sectional study on pregnant who delivered between $(1-6)$ weeks and non pregnant women as a control. Result: There was significant difference between TG of the exposed group $(0.87 \pm 0.29) \mathrm{mmol} / \mathrm{L}$ versus the controls $(0.75 \pm 0.31) \mathrm{mmol} / \mathrm{L} p=0.04$. T.CHOL was also significant between the exposed $(4.45 \pm 0.75) \mathrm{mmol} / \mathrm{L}$ and controls $(4.03 \pm 1.04) \mathrm{mmol} / \mathrm{L} p=$ 0.029. Comparing LDL-C of both groups was $(2.71 \pm 0.79) \mathrm{mmol} / \mathrm{L}$ for the cases and $(2.26 \pm 0.75) \mathrm{mmol} / \mathrm{L}$ for the controls a $p=0.005$. Also there was a significant difference between HDL-C of the exposed $(1.28 \pm 0.33) \mathrm{mmol} / \mathrm{L}$ and controls $(1.45 \pm 0.44) \mathrm{mmol} / \mathrm{L} p=0.044$. There was no correlation between baby's weight and maternal BMI, $p=0.950$. Postnatal lipids did not also show relationship with baby's weight. Dyslipidaemia during the postpartum period did not reflect a subsequent increase in birth weight. Conclusion: Generally, the study demonstrated strongly that BMI does not affect birth weight especially in women who are overweight and obese. More so, dyslipidaemia during the postpartum period $(1-6)$ weeks did not correlate or reflect a subsequent increase in birth weight and a possible obesity in later life.
\end{abstract}

\section{Subject Areas}

Global Health, Health Policy, Nutrition, Pediatrics, Public Health 


\section{Keywords}

Pregnancy Weight Retention, Macrosomia, Dyslipidaemia, Obesity

\section{Introduction}

Maternal hypertriglyceridemia is a characteristic feature during pregnancy and usually appears in marked amounts, whereas rises in phospholipids and cholesterol are smaller. This change corresponds not only to an increment in VLDLs but also to an enrichment of triglycerides in other lipoprotein fractions that normally do not transport them, such as low density lipoproteins (LDLs) and high density lipoproteins (HDLs).

Although triglycerides do not directly cross the placental barrier [1], essential fatty acids (EFA) derived from maternal diet, which are transported as triglycerides in triglyceride-rich lipoproteins in maternal plasma [2], must become available to the fetus. Placental trophoblast cells have been shown to express both very low-density apo-E receptors as well as LDL receptor-related proteins. In addition, they also express LPL activity, phospholipase A2 and intracellular lipase activity [3].

Maternal pre-pregnancy Body mass index (BMI) has been found to be related to pregnancy related complications and macrosomia. It is however frequently used as an indicator of the conditions experienced in utero with possible impacts on infant birth weight as well. The relationship between maternal pre-pregnancy BMI and offspring birth weight was examined among 58,383 Norwegian women by [4]. More so; maternal pre-pregnancy weight and height were self-reported and infant birth weight also obtained per medical records made available. Results indicated that offspring birth weight increased with a subsequent increase in maternal pre-pregnancy BMI. Infant birth weight was seen also to increase by 25.9 $\mathrm{g}(95 \% \mathrm{CI}: 25.0,26.9)$ for every increase in maternal pre-pregnancy BMI $\left(1 \mathrm{~kg} / \mathrm{m}^{2}\right)$.

Birth weight is said to be positively correlated with delivery weight and gestational weight gain in primiparous females [5]. However, no correlations were observed between the birth weight of the infant and pre-pregnancy weight or BMI.

In a German mother-infant pairs study, where maternal pre-pregnancy was calculated based on self-reported body weight before pregnancy and maternal height obtained from medical records available with results showing a high level of macrosomia (OR: 1.6, 2.5) in 21 overweight and obese women with an association highly independent of the child's gender and gestational age [6].

\section{Methodology}

\subsection{Study Area}

The study was conducted at the Volta Regional Hospital (VRH) and the Ho Municapial Hospital (HMH) between November 2015 and May 2016. The VRH serves as a referral point for all other hospitals in the Volta region and the HMH serves as a primary health facility. They both serve a varying cluster of people from various parts of the region and beyond. 


\subsection{Study Design}

This was a prospective cross sectional study. Blood samples $(5 \mathrm{ml})$ were taken from 52 women who delivered between one to six weeks and from 50 non pregnant women. Sera was then separated and stored at $-21^{\circ} \mathrm{C}$ until analysis was done. The sample size was determined by calculations based on the following formula; $N=\frac{Z^{2}(p q)}{d}$ [7]. The statistical certainty chosen is $95 \%$ level of confidence, hence $z=1.96$. The estimated rate (p) for the association was estimated at $5 \%$.

Various anthropometric measurements on baby and mothers were taken. Lipid profiles of all participants were determined. Prior to the test procedure the women were required to fast overnight between 10 - 16 hours.

Standard Stadiometer (McArthur Medical Sales Inc, Canada) was used for the anthropometric measurements. The height of participants were taken using the stadiometer and with the age of participants. Participants were then asked to simultaneously stand on the foot electrode of a weighing balance and firmly hold the holder with arm stretched forward horizontally. Within some few seconds the weighing balance generated the weight which was digitally displayed and BMI calculated.

\subsection{Data Entry, Management and Analysis}

Hospital records available for each participant were used to obtain their demographic data. Data obtained was documented in a record book and later computed into Microsoft excel and analysed with statistical software SPSS 23.0 for windows (SPSS Inc., Chicago, IL, USA). Data analysis consist of tallying responses to each item, computation of frequencies and percentage of data in order to come out with the findings.

\subsection{Ethical Issues}

Ethical clearance was obtained from the ethical and protocol review committee of the VRH and HMH. Written consent was obtained from all participants who agreed to partake in the study after they had been thoroughly informed. Confidentiality of participants' information and data results from the study were assured.

\section{Results}

A total of one hundred and two (102) participants were recruited for the study. This included 15 - 20 years 7 (35.0\%) for the case group and 13 (65.0\%) for control group. Also for ages $21-25$ years $20(39.2 \%)$ for the case and $31(60.8 \%)$ controls represented. Ages 26 - 30 years gave 11 (61.1\%) for individuals used for the case and 7 (38.9\%) for control group. More so, 6 (12.5\%) of the case group were single against the control group of $42(87.5 \%)$ who were also single. 44 $(81.5 \%)$ of the case group were also married as against $10(18.5 \%)$ of the control subjects who were also married.

Among the participants, $82.9 \%$ had primary education, $69.6 \%$ had secondary education, and $11.4 \%$ had tertiary level of education. 
The results indicates that overweight and obese women had babies who were heavier and macrosomic (4.00 $\mathrm{kg}$ and above) than women with normal BMI (Table 1).

\subsection{General Comparison of Means among Study Subjects}

The mean age of the cases was significantly higher than controls $(25.6 \pm 5.5$ years vs $22.5 \pm 2.5$ years), $p \leq 0.001$. The mean BMI was not significantly different between the exposed and the non-exposed $\left(24.94 \pm 4.43 \mathrm{~kg} / \mathrm{M}^{2}\right.$ vs $26.61 \pm 5.42$ $\left.\mathrm{kg} / \mathrm{M}^{2}, p=0.091\right)$

Mean triglyceride was $(0.87 \pm 0.29 \mathrm{mmol} / \mathrm{L})$ for the exposed group and $(0.75 \pm$ $0.31 \mathrm{mmol} / \mathrm{L})$ for the control group. LDL-cholesterol was $(2.71 \pm 0.79 \mathrm{mmol} / \mathrm{L})$ for the exposed group and this was apparently higher than that for the control group $(2.26 \pm 0.75 \mathrm{mmol} / \mathrm{L})$. Similarly, Total cholesterol was $(4.45 \pm 0.75$ $\mathrm{mmol} / \mathrm{L}$ ) for the exposed group which was higher than that in the control group $(4.03 \pm 1.04 \mathrm{mmol} / \mathrm{L})$. Finally, HDL-cholesterol also recorded an average mean of $1.28 \pm 0.33 \mathrm{mmol} / \mathrm{L}$ for the exposed group marginally lower than what was observed in the control group $(1.45 \pm 0.44 \mathrm{mmol} / \mathrm{L})$.

Among the risk factors BMI showed no significant difference $(p=0.091$ among the subject group. Others like Age, LDL-cholesterol, HDL-cholesterol, Total-cholesterol and Triglyceride all showed significant difference between groups.

Results of correlation analysis among the measured risk factors are shown in Table 3 at 95\% confidence interval, BMI of postnatal women showed no significant association with babies weight with $(p=0.950)$ (Table 2 and Table 3 ).

Table 1. Relationship between maternal weight and the weight of the baby.

\begin{tabular}{|c|c|c|c|}
\hline Parameters & $2.00-3.00 \mathrm{~kg}$ & $3.00-4.00 \mathrm{~kg}$ & $4.00 \mathrm{~kg}$ above \\
\hline Normal & $12(60.0 \%)$ & $8(40.0 \%)$ & $0(0.0 \%)$ \\
\hline Overweight & $8(66.7 \%)$ & $3(25.0 \%)$ & $1(8.3 \%)$ \\
\hline Obesity I & $6(50.0 \%)$ & $5(41.7 \%)$ & $1(8.3 \%)$ \\
\hline Obesity II & $1(33.3 \%)$ & $1(33.3 \%)$ & $1(33.3 \%)$ \\
\hline Extreme Obesity & $0(0.0 \%)$ & $0(0.0 \%)$ & $1(100.0 \%)$ \\
\hline
\end{tabular}

Table 2. Comparison of means between cases and controls.

\begin{tabular}{ccccc}
\hline Parameters & Total & Case & Control & P-Value \\
\hline AGE & $24.02 \pm 4.52$ & $25.6 \pm 5.52$ & $22.5 \pm 2.54$ & $<0.001$ \\
BMI & $25.76 \pm 4.99$ & $26.61 \pm 5.42$ & $24.94 \pm 4.43$ & 0.091 \\
CHOL & $4.23 \pm 0.94$ & $4.45 \pm 0.75$ & $4.03 \pm 1.04$ & 0.029 \\
TRIG & $0.8 \pm 031$ & $0.87 \pm 0.29$ & $0.75 \pm 0.31$ & 0.044 \\
LDL & $2.47 \pm 0.79$ & $2.71 \pm 0.79$ & $2.26 \pm 0.75$ & 0.005 \\
HDL & $1.37 \pm 0.40$ & $1.28 \pm 0.33$ & $1.45 \pm 0.44$ & 0.044 \\
\hline
\end{tabular}

Data are presented as mean \pm standard deviation of the mean. AGE, BMI (Body Mass Index), CHOL (Total Cholesterol), TRIG (Triglycerides), HDL (High Density Lipoprotein), LDL (Low Density Lipoprotein) were calculated using the Friedewald equation. P-value is significant at 0.05 . 
Table 3. Correlation between BMI and babies weight.

\begin{tabular}{ccccc}
\hline Parameter & Mean & SD & $\mathrm{R}$ & $P$-Value \\
\hline BMI of Postnatal women & 26.61 & 5.42 & 0.009 & 0.950 \\
Baby Weight & 2.97 & 0.42 & & \\
\hline
\end{tabular}

\subsection{Relationship between Birth Weight and Postnatal Lipids of the Women}

Total cholesterol showed a significant difference with Triglyceride, HDL-cholesterol, and LDL-cholesterol with no significant difference seen with Babies age. Triglyceride also showed an association with LDL-cholesterol with no significant difference between HDL-cholesterol and Babies age. Similarly, HDL and LDLcholesterol showed no significant difference between the groups. Table 4 contains the summarized results.

\subsection{Correlation between Babies Weight and Postnatal Lipids of Women for the Groups}

Results indicate no significant difference between babies' weight and Total Cholesterol, Triglyceride, HDL cholesterol and LDL cholesterol (Table 5).

\section{Discussion}

This study was conducted in a mixed ethnic population in the Volta regional hospital and Ho municipal hospital and highlights some novel and potential clinically important aspects of obesity and dyslipidaemia. Most importantly, the results suggests no correlation between babies weight and women with high BMI thus overweight (BMI $\left.25-30 \mathrm{~kg} / \mathrm{m}^{2}\right)$, obese $\left(B M I>30 \mathrm{~kg} / \mathrm{m}^{2}\right)$ and women with low BMI (BMI $\left.<18.5 \mathrm{~kg} / \mathrm{m}^{2}\right)$. This is in contrast to a recent study conducted in the North America which reported an increase in mean birth weights, particularly those macrosomic (Birth weight $>4.0 \mathrm{~kg}$ ) [8]. Percentage of macrosomic newborns have been on the rise particularly because of factors such as decreased maternal smoking, an increase in gestational diabetes and increasing maternal BMI have all been implicated and the increase in maternal weight before delivery as the factors most strongly correlated with the increase in birth weight [9].

Comparing with the Total cholesterol and HDL-C in 52 women who had never been pregnant had slight decreases in HDL-C and Total cholesterol.

The increased mean value of BMI among the exposed group could partly explain the rise in triglycerides, low density lipoprotein and total cholesterol and the significant positive correlation compared to the control group between these measurements, because increased body weight/BMI is associated with increased body fat levels. The significantly raised levels of lipid fractions especially Total Cholesterol, LDL-C and TGs as seen from this work could partly explain. However during the postpartum period there was significantly normal level in HDLC Levels of subjects when compared to the non-pregnant subjects. It is worth noting that the mean value was still higher than in the non-pregnant women even though the differences were statistically significant. This phenomenon may 
Table 4. Correlation between Babies age after birth and postnatal lipids.

\begin{tabular}{cccccc}
\hline & CHOL & TRIG & HDL & LDL & BABIES AGE \\
\hline CHOL & - & 0.006 & 0.038 & 0.000 & 0.223 \\
TRIG & - & - & 0.479 & 0.012 & 0.165 \\
HDL & - & - & - & 0.261 & -0.060 \\
LDL & - & - & - & - & 0.778 \\
\hline
\end{tabular}

Data are presented as Babies Age, CHOL (Total Cholesterol), TRIG (Triglycerides), HDL (High Density Lipoprotein), LDL (Low Density Lipoprotein) were calculated using the Friedewald equation. P-value is significant at 0.05 .

Table 5. Correlation between babies weight and postnatal lipids estimated.

\begin{tabular}{ccccc}
\hline Babies Weight & CHOL & TRIG & HDL & LDL \\
\hline Babies Weight & 0.618 & 0.199 & 0.928 & 0.636 \\
CHOL & & 0.006 & 0.038 & 0.000 \\
TRIG & & 0.479 & 0.012 \\
HDL & & & 0.083 \\
\hline
\end{tabular}

Data are presented as Babies weight, CHOL (Total Cholesterol), TRIG (Triglycerides), HDL (High Density Lipoprotein), LDL (Low Density Lipoprotein) were calculated using the Friedewald equation. P-value is significant at 0.05 .

be explained that, the rise in reproductive hormones which are the main cause of hyperlipidemia during pregnancy have reached significantly low levels in the postpartum period. Significantly lower levels of these lipids however were seen when compared to the non-pregnant women. Mean value of total cholesterol increased at the postnatal period. There was significant statistical difference between cholesterol levels of non-pregnant subjects and the women who have delivered few weeks after pregnancy $(p<0.05)$. These findings are at variance with findings of [10]. Low density lipoprotein had similar pattern with total Cholesterol. The mean of the postnatal women was statistically different when compared with the mean of the non-pregnant women $(p<0.05)$.

\section{Conclusions}

Generally, the study demonstrated strongly that BMI does not affect birth weight especially in women who are overweight and obese. More so, dyslipidaemia during the postpartum period $(1-6)$ weeks did not correlate or reflect a subsequent increase in birth weight and a possible obesity in later life. A longitudinal study should be repeated with larger sample size and should include monitoring of changes in lipid pattern, from first trimester to delivery so as to determine major metabolic dysregulations in pregnancy and their impact on babies' growth and health.

The study also recommends that, further studies be conducted to find the health risk associated with hyperlipidaemia during the various trimesters since it could have possible influences on the birth weight of newborns. 


\section{References}

[1] Herrera, F., Lozano, M. and Verdegay, J.L. (1998) Tackling Real-Coded Genetic Algorithms: Operators and Tools for Behavioural Analysis. Artificial Intelligence Review, 12, 265-319. https://doi.org/10.1023/A:1006504901164

[2] Herrera, E. (2002) Lipid Metabolism in Pregnancy and Its Consequences in the Fetus and Newborn. Endocrine, 19, 43-55. https://doi.org/10.1385/ENDO:19:1:43

[3] Judd, L.L., Akiskal, H.S., Maser, J.D., Zeller, P.J., Endicott, J., Coryell, W., et al. (1998) Major Depressive Disorder: A Prospective Study of Residual Subthreshold Depressive Symptoms as Predictor of Rapid Relapse. Journal of Affective Disorders, 50, 97-108. https://doi.org/10.1016/S0165-0327(98)00138-4

[4] Stamnes Koepp, U.M., Frost Andersen, L., Dahl-Joergensen, K., Stigum, H., Nass, O. and Nystad, W. (2012) Maternal Pre-Pregnant Body Mass Index, Maternal Weight Change and Offspring Birthweight. Acta Obstetricia et Gynecologica Scandinavica, 91, 243-249. https://doi.org/10.1111/j.1600-0412.2011.01321.x

[5] Chiba, T., Ebina, S. and Kashiwakura, I. (2013) Influence of Maternal Body Mass Index on Gestational Weight Gain and Birth Weight: A Comparison of Parity. $E_{X-}$ perimental and Therapeutic Medicine, 6, 293-298.

[6] Kalk, P., Guthmann, F., Krause, K., Relle, K., Godes, M., Gossing, G., et al. (2009) Impact of Maternal Body Mass Index on Neonatal Outcome. European Journal of Medical Research, 14, 216.

[7] Snedecor, G. and Cochran, W. (1989) Analysis of Variance: The Random Effects Model. Statistical Methods, Iowa State University Press, Ames, IA, 237-253.

[8] Ørskou, J., Kesmodel, U., Henriksen, T.B. and Secher, N.J. (2001) An Increasing Proportion of Infants Weigh More than 4000 Grams at Birth. Acta Obstetricia et Gynecologica Scandinavica, 80, 931-936. https://doi.org/10.1034/j.1600-0412.2001.801010.x

[9] Catalano, P., Ashmead, G., Huston-Presley, L. and Amini, S. (2005) The Obesity Cycle Comes Full Circle: Increasing Trends in Birth Weight. Diabetes in Pregnancy Study Group 37 th Annual Meeting, Myconos, Greece, 15-18.

[10] Sattar, N., Greer, I.A., Galloway, P.J., Packard, C.J., Shepherd, J., Kelly, T., et al. (1999) Lipid and Lipoprotein Concentrations in Pregnancies Complicated by Intrauterine Growth Restriction. The Journal of Clinical Endocrinology \& Metabolism, 84, 128-130. https://doi.org/10.1210/jc.84.1.128

Submit or recommend next manuscript to OALib Journal and we will provide best service for you:

- Publication frequency: Monthly

- 9 subject areas of science, technology and medicine

- Fair and rigorous peer-review system

- Fast publication process

- Article promotion in various social networking sites (LinkedIn, Facebook, Twitter, etc.)

- Maximum dissemination of your research work

Submit Your Paper Online: Click Here to Submit

Or Contact service@oalib.com 